Journal of Transport and Land Use 1:1 (Summer 2008) pp. 65-87

Available at http://jtlu.org

\title{
Integral cost-benefit analysis of Maglev projects under market imperfections
}

\author{
J. Paul Elhorst and Jan Oosterhaven \\ University of Groningen, The Netherlands a
}

\begin{abstract}
This article gives an integral evaluation of four Dutch magnetic levitation proposals (Maglevs), explicitly considering market imperfections and cross-border effects. The outcomes of the evaluation provide policy information on the interregional redistribution of employment and population, and on the national welfare effects of the projects. This article also compares the results of an integral cost-benefit analysis with those of a traditional cost-benefit analysis of the direct transport effects only, and concludes that the additional economic benefits due to market imperfections and cross-border effects vary from $-1 \%$ to $+38 \%$ of the direct transport benefits, where the ratio depends on the type of regions connected and the future conditions of the market economy. Finally, it concludes that none of the Maglev projects should be considered socially desirable.
\end{abstract}

Keywords: Magnetic levitation, cost-benefit analysis, market imperfections, the Netherlands

\section{Introduction}

Any proposal for significant new transport infrastructure requires a thorough and systematic appraisal process. The SACTRA report (1999, pp. 179-189) recommends that this process be structured by the following questions:

1. What is the rationale for the transport improvement?

2. What is the pattern of gains and losses, in economic activity and jobs, which will arise from the transport improvement?

3. What are the welfare effects of the transport improvement, calculated by a conventional partial cost-benefit analysis and by an integral cost-benefit analysis including environmental effects and wider economic effects.

aj.p.elhorst@rug.nl

Copyright 2008 J.P. Elhorst and Jan Oosterhaven.

Licensed under the Creative Commons Attribution - NonCommercial License 3.0. 
The aim of this article is to appraise a new mode of high speed ground transportation, magnetic levitation (Maglev), by means of an analysis of four different Dutch Maglev proposals under different economic conditions, and to compute the ratio of the additional welfare effects — due to market imperfections and cross-border effects— to the direct transport benefits.

The Dutch government has contemplated the construction of two Maglev projects, an urban-conglomeration project and a core-periphery project, each with two variants. A description of and the rationale for these projects is presented in Section 2. The Maglev projects are part of a larger set of policy proposals covering different rail systems (also regular and high-speed rail), different alignments and stations, different service levels (frequency, schedule, waiting time), and different price levels. This article reports on the evaluation of the four Maglev projects only, because a thorough and systematic evaluation of this new transport mode is not yet available in the literature.

Vuchic and Castello (2002) have compared critical system characteristics of Maglev technology with regular high-speed rail, including investment costs, operating and maintenance costs, and energy consumption, but they have not carried a cost-benefit analysis (CBA). Van Wee et al. (2003) have explored methods for more completely incorporating environmental effects into CBA and have illustrated this with, inter alia, data on Maglev proposals. This paper considers the impact of a much broader set of market imperfections on CBA than is usually done.

Two seminal official reports (SACTRA 1999; CPB/NEI 2000) have pointed out that a conventional partial CBA of the direct transport costs and benefits of new infrastructure may underestimate or overestimate the total costs and benefits, because such a partial CBA can only be justified by the assumption of a closed economy with perfect competition. ${ }^{1}$ To understand the need for these two assumptions, it is important to make a distinction between direct and indirect effects (in the UK called 'wider effects'). Direct economic effects include cost and benefits for the owner, the operator and the users of the transport improvement, such as investment costs, exploitation costs and revenues, and transport costs and time benefits for freight and people given existing locations of firms and people. Indirect economic effects include costs and benefits of the transport improvement that are passed on through markets to producers and consumers in other markets, which may lead to relocation of firms and people, and the subsequent interregional generation and redistribution of income and employment (Rietveld and Nijkamp 2000; Oosterhaven and Knaap 2003). In addition to these direct and indirect effects through markets, there will be direct and indirect effects that are external to the market, such as changes in congestion, safety, pollution and other

\footnotetext{
${ }^{1}$ The EU guide on CBA also mentions this problem but only in passing (EC 2002, p. 77) and advocates excluding possible additional wider economic benefits from the calculation of profitability indicators. However, since infrastructure in problem regions often is advocated precisely to generate indirect economic effects, they should be treated seriously.
} 
environmental indicators (cf. SACTRA 1999; CPB/NEI 2000; Rothengatter 2000).

The perfect competition and closed economy assumptions provide an important benchmark, because the calculation of direct transport benefits is sufficient as an estimate of total economic benefits if these assumptions hold. Under these assumptions, the usual passing on of transport cost and benefits to producers and consumers in other markets does not change the size of welfare effects. Consequently, it is possible to ignore the difficult task of measuring the indirect economic effects, since they do not change the efficiency judgment on the project at hand.

By contrast, when the benchmark is not valid, responses of economic agents require explicit modeling attention as they may generate—-possibly large-additional welfare gains or losses (see Jansson 2000, for a graphical demonstration). Theoretical simulation studies provide some indication that the "additional economic to direct transport benefits" ratio may be considerable (SACTRA 1999, p. 101), but convincing factual evidence is lacking. An integral social cost-benefit analysis, in addition to the usual external effects, relaxes the assumption of perfect competition where relevant (such as on product, labor and housing markets) and considers cross-border effects in order to include the possibly large additional costs or benefits related to the indirect responses of economic agents.

The contribution of this paper to the literature is twofold. First, the study discussed herein is one of the first to attempt to measure the comprehensive net total of all social costs and benefits of new transport infrastructure, taking account of the effects of imperfect competition and an open economy. The results show that a uniform ratio to derive the additional economic benefits from the direct transport benefits does not exist; the ratio proves to be dependent on the type of regions connected, the alignment at hand, the type of market imperfections taken into account, and the future state of the market economy. Second, it is one of the first studies that attempts to measure this net total for magnetic levitation systems.

This paper is organized along the lines recommended in the SACTRA report. Section 2 contains a description of the Maglev projects and their policy aims. Section 3 gives a brief description of the modeling set-up used to calculate the indirect economic effects; it also summarizes which regions gain and which lose as a result of the Maglev projects and, in addition, evaluates whether the stated public aims are met. Section 4 describes the valuation of the direct costs and benefits and external effects in general terms, and the valuation of the indirect economic effects in more detail, with special attention to the issue of how market imperfections are incorporated. Further implications, conclusions and some words of caution are presented in Section 5. 


\section{The four Maglev rail projects}

Figure 1 shows the proposed alignments and stations of the two Maglev projects, each with two variants:

1. An inner ring and an outer ring connecting the four largest cities of the Netherlands (Amsterdam, the Hague, Rotterdam and Utrecht). These cities are all located in the Randstad, a region consisting of the three western provinces and comprising the economic core of the Netherlands. This region is highly urbanized with high densities of both people and businesses. The inner ring is shorter as it serves the edges of Rotterdam and Utrecht, while the outer ring has more stations and also serves the city centers of Rotterdam and Utrecht;

2. A direct connection between Schiphol Airport (near Amsterdam) and Groningen. Groningen is the largest city of the three northern provinces, which constitute a peripheral region with a rural character, even though the income share from agriculture is rather small. The connection either runs over the 32 kilometer long dike that constitutes the north-west shore of the large lake in the middle of the country, or it runs south-east of it through the new polders of the province of Flevoland, with Almere, Lelystad and Emmeloord.

In sum, we analyze four quite different Maglev projects.

The major aim of a fast rail link within the Randstad is to improve its internal accessibility by public transport. This in turn is intended to reduce traffic congestion and also to improve the Randstad's internal accessibility by car. Both may strengthen the Randstad's competitive position in attracting internationally mobile economic activities. Second, compared to other regions in the Netherlands, the need for space for new residential areas and industrial sites is much more urgent in the Randstad. With the help of new fast rail links, it may be possible to direct the urbanization process away from the remaining vulnerable agricultural and natural areas within the so-called "Green Heart" of the Randstad, which is the secondary aim of this link.

The major aim of a fast rail link between the Randstad and the North is to stimulate the lagging Northern economy. With a fast rail link, people may choose to continue living in the North while working in the Randstad. This would increase demand for locally produced goods, initiating a multiplier process leading to increased regional production and employment. A fast rail link may also lower the prices of services to and from firms located in the North, possibly shifting the competitive balance in favor of locations in the North in spite of the 'two-way road' argument (SACTRA 1999, p.16). Both effects are thought to further economic development. A secondary aim of

a fast rail link between the Randstad and the North is to relieve the Randstad's capacity constraints in transport, land, and labor markets, which presently result in loss of time, 

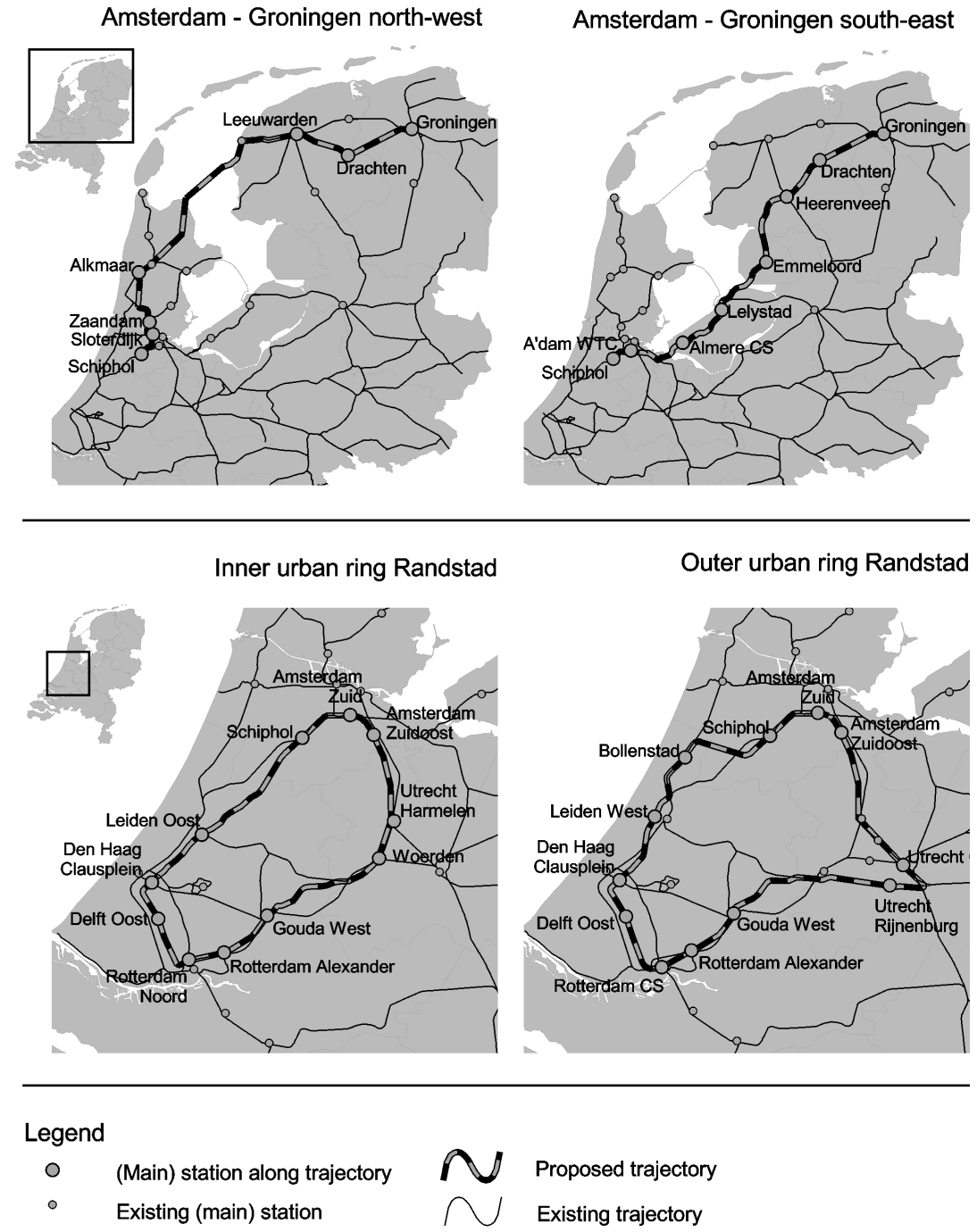

Figure 1: Proposed four magnetic levitation alignments with stations

high transport costs, high housing prices, high cost of living, and labor shortages (cf. Elhorst et al. 1999).

\section{Indirect economic effects}

The modeling of the indirect economic effects of the four Maglev projects involves the use of five different models, four of which were specifically developed for this study 
by different teams of researchers. The basic overall modeling philosophy is such that the endogenous outcomes of a particular model in the causal chain of effects enter the subsequent model as exogenous inputs, and that the same variable is not modeled twice (see Oosterhaven and Romp 2003). The five base models are detailed elsewhere. Section 3.1 summarizes their main function and how they are combined to project the interregional redistribution of the working population and labor demand that may be expected as a result of implementing each of the four Maglev projects separately. The redistribution effects are summarized in Section 3.2 in order to answer the question of how well each of the four projects serves the policy aims discussed above.

\subsection{Modeling set-up}

The indirect economic effects in this study are modeled at the municipal level as two independent main indirect effects and two derived interaction effects; in both cases one effect is on the size of the working population and the other effect is on the size of labor demand (see Figure 2). All four Maglev projects are evaluated in comparison with a long-term spatial economic baseline scenario for the Dutch economy, which is based on a moderate long-term macroeconomic growth scenario, labeled as the "European Co-ordination" scenario (CPB 1997).

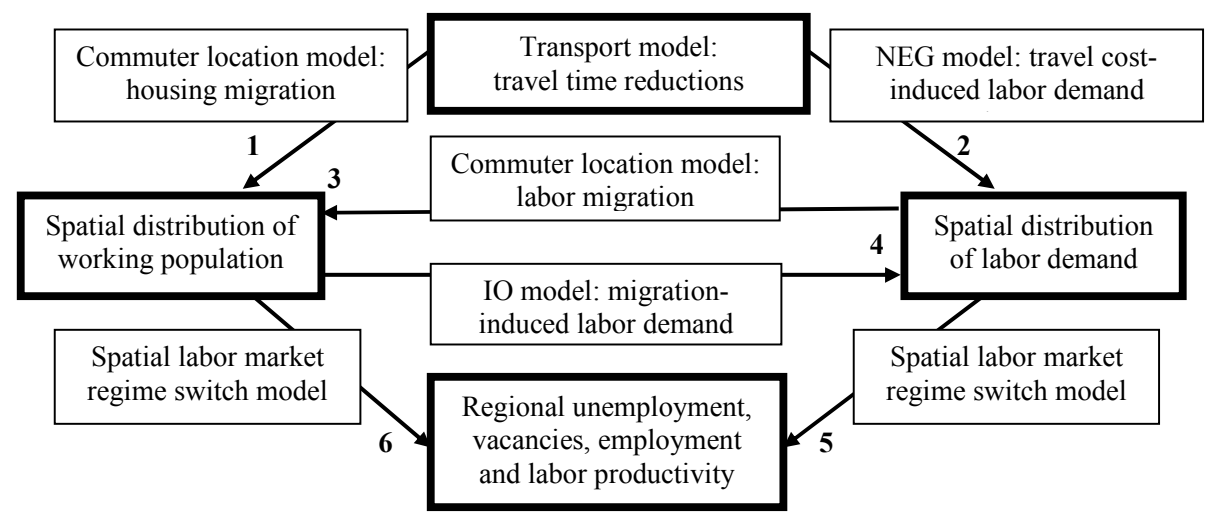

Figure 2: Modeling scheme for estimating the indirect economic effects

The expected travel times in 2020 with and without each of the four Maglev projects provide a starting point for the estimation of indirect economic effects. These travel times are derived from a standard four-stage transport model, which uses fixed spatial distributions of employment and population (see Daly 2000, section 2.2, for details). One of the most striking transport characteristics of both core-periphery Maglevs is the reduction of total travel time via public transport below its counterpart by 
private car, even during non-rush hours. ${ }^{2}$ In the urban-conglomeration projects, the public transport travel times, although much lower with the Maglevs than without, still remain higher than their counterparts by private car.

The first main indirect effect (arrow 1) relates to housing migration of the working population $\left(\Delta W_{\text {housing }}\right)$. When travel times diminish, people may increase the quality of their housing accommodation and living environment, by increasing their commuting journey length, without changing their commuting journey time. This principle has been used to develop a commuter location model (CLM) that takes actual commuting time behavior as given and then predicts where people choose to live given the location of their jobs $\left(J_{\text {base }}\right)$ (see Elhorst and Oosterhaven 2006, for details). The difference between the predictions based on commuting times in the baseline scenario ( $\left.T_{\text {base }}\right)$ and in the project variants $\left(T_{\text {maglev }}\right)$ gives the estimation of housing migration:

$$
\Delta W_{\text {housing }}=C L M\left(J_{\text {base }}, T_{\text {maglev }} \text {, etc. }\right)-C L M\left(J_{\text {base }}, T_{\text {base }} \text {, etc. }\right)
$$

The second main indirect effect (arrow 2) relates to employment changes induced by travel costs. If the transport costs of inputs and outputs change differentially in different locations, the optimal location and production size of firms is expected to change. "New economic geography" (NEG) has pointed out that monopolistic competition (with 'love of variety' and increasing returns to scale) in transport-using sectors causes traditional location approaches to produce inaccurate estimates. There are two fundamentally different types of NEG models. In the "footloose labor" model developed by Krugman (1991), locations close to markets pay higher real wages than locations farther out. They consequently attract labor, which further enlarges the market and causes a further concentration of economic activity. The forces of concentration depend on the level of trade costs, the proportion of the population that works in the monopolistically competitive sector and is mobile in response to real wage differences, and the elasticity of substitution between the varieties produced within the monopolistically competitive sector. In the "vertically linked interindustry" model developed by Venables (1996), the process of cumulative causation is not driven by footloose labor but by cost and demand linkages between multiple sectors. Firms in downstream industries will have lower intermediate input costs if they locate close to upstream firms, while market access draws upstream industries to locations with relatively many downstream firms and consumers.

In this study, an interindustry type of NEG model has been formulated and estimated with data from twelve bi-regional input-output tables (Knaap and Oosterhaven 2008). The reason for not using the footloose labor model is that wages in the Netherlands are determined by national single-industry agreements, which are binding by law

\footnotetext{
${ }^{2}$ It is $96-100$ minutes by Maglev, including entrance and egress time, compared to 135 minutes by car over a distance of almost $190 \mathrm{~km}$ between the endpoints of the line.
} 
to all firms and workers throughout the country. In other words, sectoral wages are assumed to be equal throughout the country, and regional labor supply is assumed to follow regional labor demand. The NEG model is used to forecast labor demand in the baseline scenario $\left(T_{\text {base }}\right)$ and in each project variant $\left(T_{\text {maglev }}\right)$, given the location of working people $\left(W_{\text {base }}\right)$. The difference between these forecasts is used as an estimation of the travel cost-induced employment changes:

$$
\Delta J_{\text {travel cost }}=N E G\left(T_{\text {maglev }}, W_{\text {base }}, \text { etc. }\right)-N E G\left(T_{\text {base }}, W_{\text {base }}, \text { etc. }\right)
$$

The first derived effect (arrow 3) is the residential choice reaction of the working population to the travel cost-induced changes in labor demand $\left(\Delta J_{\text {travel cost }}\right)$, and is labeled as labor migration $\left(\Delta W_{\text {labor }}\right)$. Note that the commuter location model predicts housing migration as a result of changes in travel times with a given level of employment (1), whereas this run of the commuter location model measures labor migration as a result of changes in employment opportunities:

$$
\Delta W_{\text {labor }}=C L M\left(J_{\text {base }}+\Delta J_{\text {Travel cost }}, T_{\text {maglev }}, \text { etc. }\right)-C L M\left(J_{\text {base }}, T_{\text {maglev }} \text {, etc. }\right)
$$

It should be stressed that labor migration has been restricted to higher-educated labor only (35\% of the total labor force), since workers with low and medium levels of education are assumed to be immobile. Total migration then simply equals the sum of housing migration (1) and labor migration (3).

The second derived effect (arrow 4) relates changes in consumption-induced employment $\left(\Delta J_{\text {consumption }}\right)$ to the total migration of workers by means of an interregional input-output model (IOM) (see Oosterhaven 2005 for details):

$$
\Delta J_{\text {consumption }}=\operatorname{IOM}\left(\Delta W_{\text {housing }}+\Delta W_{\text {labor }}\right)
$$

The total labor demand changes then simply equal the sum of the travel costinduced employment effect (2) and consumption-induced employment effect (3).

The above summarized first-order indirect economic effects are obtained when the arrows 1 to 4 in Figure 2 are passed through once. In principle, it would be possible to take account of higher-order effects and to go on until convergence occurs. However, since these higher-order effects appeared to be relatively small, we have used the firstorder effects only.

\subsection{Indirect economic impacts and policy aims}

The first aim of the urban-conglomeration proposals is to strengthen the Randstad's international competitive position. Due to travel cost-induced and consumptioninduced interregional employment redistribution within the Netherlands, employment in the Randstad will increase by 1,750 jobs in the inner ring variant and by 
2,050 jobs in the outer ring variant.International redistribution of employment is independently estimated to lead to a further increase of about $1,300-1,420$ jobs in the Randstad (BCI 2001). The second objective is to direct the urbanization process away from the remaining http://www.marriedtothesea.com/042408/better-hide-thisone.gifvulnerable agricultural and natural areas within the Randstad. In both variants, approximately 1,500 working people (housing and labor migrants) will leave the Randstad. In sum, the Randstad in total benefits little in terms of both jobs and reduced population pressure.

When looking at regions outside the Randstad and at intra-regional changes within the Randstad, it is found that both variants strengthen the process of suburbanization. Within the four big agglomerations, the central municipalities of Amsterdam, Rotterdam, the Hague and Utrecht experience population decreases compared to the baseline scenario, whereas surrounding municipalities that are close to a Maglev station experience population increases, even though the number of jobs in these areas decreases. This suburbanization process partly extends to the regions east of the Randstad and to a lesser extent also to the peripheral North. By contrast, the South of the Netherlands loses from a fast rail link inside the Randstad, in terms of both employment and population.

The first aim of the core-periphery proposals is to stimulate the peripheral North. Due to travel cost-induced and consumption-induced employment changes, labor demand in the North increases, with 3,600 jobs in the south-east variant and 7,350 jobs in the north-west variant. The working population (housing and labor migration) increases by 2,100 people in the south-east variant and by 5,550 people in the northwest variant. In sum, the North catches up. Furthermore, it may be concluded that the north-west variant is approximately twice as effective in promoting this outcome as the south-east variant.

The second objective of the core-periphery proposals is to relieve the pressure in the Randstad. In the south-east variant, 8,800 people will leave the Randstad and in the north-west variant only 1,300 people. So, in this respect, the south-east variant is far more effective. This last remarkable difference can be better understood by examining in greater detail what happens in the intermediate region.

The intermediate region of the north-west variant is located in the north of the Randstad, with Alkmaar as its Maglev station (see upper left panel of Figure 1). Like the North, it is a region with a rural character, a shortage of jobs, and a relatively high unemployment rate. In this scenario, the number of jobs will increase by only 100 , while the working population will decrease by 100 . By contrast, the intermediate region of the south-east variant, the polder province of Flevoland, is located halfway between the Randstad and the North (see upper right panel of Figure 1). In this case, a fast link is extremely effective: employment increases by 4,450 jobs and the working population grows by 11,500 people. There are several explanations for this remark- 
able difference. The intermediate Alkmaar region of the north-west variant will hardly attract any commuters from the Randstad due to lack of space and lack of stations, and because no new stops are planned above Alkmaar (see Oosterhaven and Romp 2003 for the rationale). By contrast, intermediate Flevoland has three stations located along the south-east variant, one of them (Emmeloord) not yet connected to the rail network. The region was reclaimed from the sea in the 1960s and 1970s, and still has a large amount of available space, while its most populous municipality (Almere) is located within 30 kilometers of Amsterdam and Utrecht. For these reasons, Flevoland is very attractive to Randstad commuters. The model results confirm this: 95 percent of migration into Flevoland consists of housing migration, and only five percent of labor migration.

\section{National costs and benefits}

Although regional gains and losses in population and jobs provide useful information for policy purposes, such as judging interregional equity impacts, they do not change the total national costs and benefits if markets for products, labor and housing are characterized by perfect competition and a closed economy. However, if these conditions are violated, an integral cost-benefit analysis covering these wider economic impacts is needed. ${ }^{3}$ In this section, most attention will be given to the estimation of the additional welfare effects due to market imperfections and cross-border effects (see Table 1 for the integral results).

\subsection{Direct benefits and costs}

Investment costs, exploitation costs and exploitation revenues are direct costs and benefits. The investment costs of the inner and the outer Randstad Maglev ring are estimated at 6,189 and 8,229 million Euros. The investment cost of the north-west and south-east Schiphol-Groningen Maglev variants are estimated at 6,501 and 5,875 million Euros. Each estimate includes a mark-up for uncertainties and risk. Exploitation costs (as a percentage of the revenues) and exploitation revenues have first been estimated by NEI $(2000,2001)$ using a transport model with the given baseline projection of the spatial distribution of employment and population. This approach is inadequate, as these distributions are not exogenous to major changes in the transport system. For this reason, the initial estimates of the transport model have been adjusted

3 There is a third reason why indirect economic effects may change the total size of the benefits estimated by means of the direct benefits of transport infrastructure only. If large projects are considered, their size may cause prices to change, and this indirect effect will have to be added to the direct effect of reduced travel times (see Boeri 1990; Bell 2003, ch. 13). In this study this effect is only considered within the NEG model, where prices decrease due to increased spatial competition and related economies of scale. 
Table 1: Social cost-benefit analysis of four magnetic levitation systems under the ECscenario: NPV in 2010, millions of Euro, price level 2000, discount rate 4\%

\begin{tabular}{|c|c|c|c|c|}
\hline & $\begin{array}{l}\text { Inner ring } \\
\text { Randstad }\end{array}$ & $\begin{array}{r}\text { Outer ring } \\
\text { Randstad }\end{array}$ & $\begin{array}{l}\text { Amsterdam- } \\
\text { Groningen, } \\
\text { north-west }\end{array}$ & $\begin{array}{l}\text { Amsterdam- } \\
\text { Groningen, } \\
\text { south-east }\end{array}$ \\
\hline \multicolumn{5}{|l|}{ Direct benefits: } \\
\hline Exploitation revenues & 480 & 2298 & 1090 & 1357 \\
\hline Time savings commuting trips & 1554 & 1667 & 662 & 650 \\
\hline Time savings other trips & 670 & 723 & 733 & 1137 \\
\hline Directly reduced congestion & 2231 & 1360 & 0 & 0 \\
\hline \multicolumn{5}{|l|}{ Additional indirect costs and benefits: } \\
\hline $\begin{array}{l}\text { Additional consumer benefits } \\
\text { (RAEM) }\end{array}$ & 54 & 80 & 129 & 284 \\
\hline Indirectly reduced congestion & 21 & 20 & 59 & 184 \\
\hline $\begin{array}{l}\text { Spatial labor market relocation } \\
\text { effects (1) }\end{array}$ & -344 & -561 & 315 & 260 \\
\hline $\begin{array}{l}\text { Spatial labor market size and } \\
\text { matching effects }\end{array}$ & 288 & 393 & 39 & 87 \\
\hline International labor market effects & 431 & 451 & 301 & 301 \\
\hline \multicolumn{5}{|l|}{ External costs and benefits: } \\
\hline Landscape-related benefits & 27 & 25 & 69 & 221 \\
\hline Emission benefits $\left(\mathrm{CO}_{2} / \mathrm{NO}_{\mathrm{x}}\right)$ & 98 & 34 & -160 & -146 \\
\hline Noise pollution & -29 & -269 & -90 & -118 \\
\hline Total benefits & 6233 & 7032 & 3312 & 4378 \\
\hline Investment costs & 6189 & 8229 & 6501 & 5875 \\
\hline Exploitation costs & 2358 & 3048 & 894 & 1094 \\
\hline Net present value $2010-2040$ & -2313 & -4244 & -4083 & -2591 \\
\hline Internal discount rate & 0.7 & -0.9 & -0.9 & -0.5 \\
\hline Net present value $2010-2060$ & -532 & -2374 & -2880 & -1020 \\
\hline Internal discount rate & 3.4 & 2.2 & 1.6 & 3.0 \\
\hline Non-monetized benefits (2) & ++ & + & ++ & ++ \\
\hline Non-monetized costs (3) & $-1+$ & $-1+$ & - & - \\
\hline Regional redistribution fair? & -10 & $-/ 0$ & ++ & + \\
\hline
\end{tabular}

(1) Inclusive of the corrections to avoid double counting part of the consumer surplus in line 3.

(2) Qualitative estimate of scale, cluster, image, and second-order economic effects.

(3) Qualitative estimate of remaining environmental and safety effects. 
on our part for the endogenous changes in employment and population, discussed in the previous section. Besides the exploitation costs and revenues of the new rail link, avoided exploitation costs and loss of revenues on existing rail links are included in the estimates.

Time savings and reduced congestion are direct benefits. One of the prime reasons to invest in infrastructure are the time benefits for people. These benefits have been estimated by means of the cost-benefit analysis "rule of half" (e.g. Button 1993, p. 183) and the use of shadow prices for the value of time (Drèze and Stern 1987):

$$
\sum_{i=1}^{N} \sum_{j=1}^{N} \sum_{k=1}^{N} 0.5 \times\left(C_{i j a m}+C_{i j a m}^{\prime}\right) \times\left(T_{i j a m}-T_{i j a m}^{\prime}\right) \times V O T_{a m}
$$

where $C_{i j a m}$ and $C^{\prime}{ }_{i j a m}$ denote the estimated flows from $i$ to $j$ of passengers engaged in activity $a$ using transport mode $m$, before and after the change in the transport system. $T_{i j a m}$ and $T^{\prime}{ }_{i j a m}$ denote the corresponding travel times and $V O T_{a m}$ denotes the value of time of activity a per transport mode $m$. Revealed preference differences in VOT s per activity and mode, and differences in the models used for different travel motives, lead to a distinction between commuting trips, commercial trips (for business and shopping purposes) and other trips, as well as between private car and public transport. ${ }^{4}$

The time savings of commuting trips by public transport have been calculated using the results for $C_{i j a m}$ and $C^{\prime}{ }_{i j a m}$ from the commuter location model, while the time savings of commercial trips and of other trips by public transport have been calculated by substituting the results of transport model (NEI 2000, 2001). The time savings by private car are due to reduced congestion. These benefits have been split into direct congestion effects, which are calculated under the assumption of a fixed spatial distribution of jobs and people, and indirect congestion effects, which are due to the changes in the spatial distributions of jobs and people. The direct congestion benefits are taken from NEI $(2000,2001)$, while the determination of the indirect congestion benefits is based on a previous study (Elhorst et al. 1999). Note that when jobs and people move from relatively overcrowded regions to relatively rural regions, as in the core-periphery projects, all associated traffic also moves and thus contributes to an indirect reduction of congestion cost.

\subsection{Additional welfare effects due to market imperfections}

The change of the consumer surplus calculated by the NEG model covers both (i) the time savings and exploitation revenues of commercial trips by public transport reported

\footnotetext{
4 Slow transport appeared to be of minor importance, as congestion and the number of people substituting car or public transport for slow transport appeared to be extremely small.
} 
above as direct benefits, and (ii) the additional welfare effects due to increased competition and increased variety of products for firms and consumers. Increased spatial competition indirectly leads to higher welfare, as the exploitation of economies of scale leads to lower prices for the products of transport-using sectors, while the increased variety directly leads to higher utility. The estimation of these welfare effects is one of the strengths of NEG models. Since utility functions per representative consumer per municipality are a core part of the model, any change of the exogenous variables in the model (i.e. matrices with travel times) can immediately be translated into a change in the total consumer surplus, which is valued at the total of Dutch private consumption expenditures. ${ }^{5}$ To compute the additional welfare, the time benefits and exploitation revenues of commercial trips are deducted from the total consumer surplus change to avoid double counting them.

Additional welfare effects on the labor market might occur due to regional imbalances. Recall that a uniform national wage level is assumed within each sector and that the reaction of the working population to the travel-cost change in labor demand is modeled assuming that segments of the labor force with low and medium education levels are immobile. Since higher-educated labor is assumed to be perfectly mobile, no additional welfare gains or losses can occur in this market segment. To measure the national efficiency effects on the market segments of the labor force with low and medium levels of education, an unemployment-vacancy regime switch model has been developed. Its basic assumption is that regions either have a labor supply surplus or a labor demand surplus. A similar type of model is used by Overman and Puga (2002) to explain regional unemployment disparities within the EU. ${ }^{6}$

First, we consider the additional welfare effects caused by the interregional shifts in labor demand, holding regional labor supply constant (indicated by arrow 5 in Figure 2 and labeled as spatial relocation benefits). When regional wages within a sector are fixed, an increase in labor demand works out quite differently when it occurs in regions with a supply surplus as opposed to regions with a demand surplus. Figure 3 describes the two different regimes. The upward sloping line is the labor supply curve reflecting the reservation wage of the unemployed. The downward sloping lines are the labor demand curves before and after the transport improvement. When the wage is fixed above its equilibrium sector-level, labor supply exceeds labor demand $(S>D=E)$, causing unemployment, $U n=S-E$ (panel a). When the wage is fixed below its equilibrium sector-level, labor demand exceeds labor supply $(D>S=E)$, causing

\footnotetext{
5 Cf. Drèze and Stern (1987, on large projects). Bell (2003, p. 339) also points out that there would be no need to estimate shadow prices when using a computable general equilibrium model. However, applied models of this sort can rarely accommodate the extensive detail concerning goods, activities, households, and institutions usually needed to evaluate a project.

6 One difference is that we assume a certain level of unemployment (frictional unemployment) at which there is full employment. Vacancies occur if labor demand increases at full employment.
} 
a. Regional labor supply surplus

b. Regional labor demand surplus

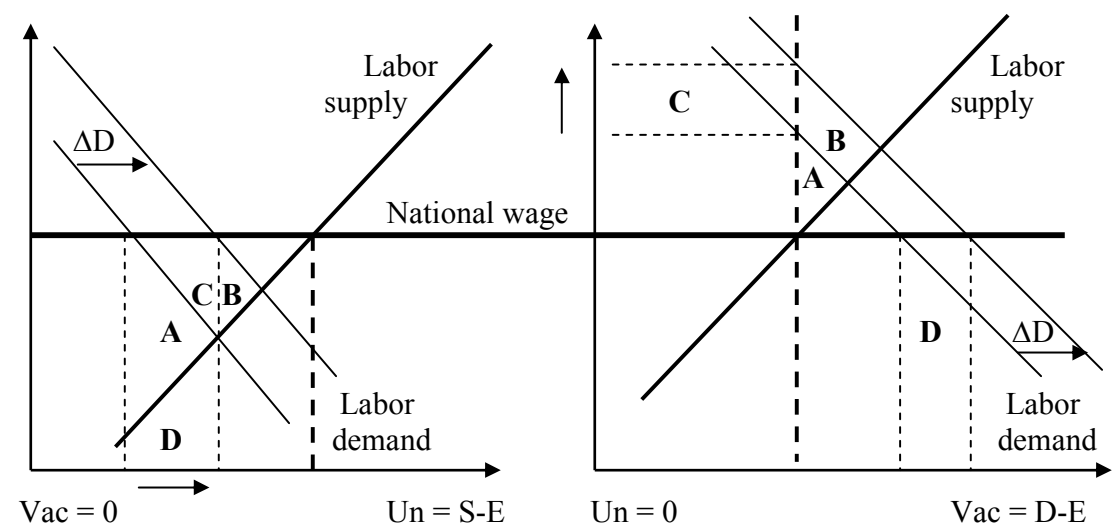

Figure 3: Effects of regional labor demand shifts under different labor market regimes

unfilled vacancies, $V a c=D-E$ (panel b).

In the case of a labor supply surplus (panel a), a demand increase of $\Delta D$ will then lead to an equally large increase in employment $\Delta E$ and a subsequent reduction of unemployment $\Delta U n$. Triangles $\mathrm{A}$ and $\mathrm{B}$ indicate the welfare forgone due to a nationally fixed regional wage within a sector, before and after the introduction of the new infrastructure. It is important to note that these triangles reflect non-realized inefficiencies, which should not be included in a cost-benefit analysis. By contrast, the area $A+C$ reflects the inefficiency that is actually taken away by the introduction of the new infrastructure. Since the change of the consumer surplus calculated by the NEG model covers the area $A+C+D$, the area $D$ (reflecting the loss of leisure of the formerly unemployed) needs to be deducted to avoid double-counting.

A different story applies in the case of a labor demand surplus (panel b). In this situation, a demand increase of $\Delta D$ will lead to an equally large increase of unfilled vacancies $\Delta V a c$, without an increase of employment. Triangles $\mathrm{A}$ and $\mathrm{A}+\mathrm{B}$ reflect the welfare forgone due to nationally fixed sectoral wages before and after the introduction of the new infrastructure, respectively. Since this constitutes a change in unrealized benefits, this change should not be included in a CBA. What should be included is the crowding-out effect of employment in less productive sectors with lower wages by employment in more productive sectors with higher wages, reflected by rectangle $C$. This crowding-out does result in an increase in the weighted average regional wage, as may be expected with large projects (Drèze and Stern 1987; Bell 2003, ch. 13). Note that this wage effect does not contradict the assumption of national single-industry agreements, as the industry mix changes. Furthermore, since the change of the con- 
sumer surplus calculated by the NEG model already covers the area $D$, the non-realized change in labor demand D needs to be deducted to avoid double counting. Finally, opposite effects occur in panels a and b of Figure 3 when labor demand shifts to the left instead of to the right.

On the other side of the labor market, spatial market size and matching benefits occur when existing firms are able to access a larger spatial pool of workers, holding regional labor demand constant (indicated by arrow 6 in Figure 2). Matching benefits occur when firms realize a better matching of skills of all educational levels, and market size benefits occur when firms in labor demand surplus regions are able to fill vacancies due to the fact that inactive members of the working-age population are willing to look for work over longer commuting distances.

Finally, independently estimated international labor market benefits occur due to increased international competitiveness, which results in an international shift of labor demand into specific Dutch regions. The estimates of these shifts are taken from BCI (2001) and TNO et al. (2000, using Bröcker 1999). The labor market regime switch model has been used to determine the extent to which these labor demand shifts result in increases in employment in the case of labor surplus regions or in increases in labor productivity and average wage in the case of labor shortage regions.

\subsection{External costs and benefits, and the NPV}

The main external costs and benefits of a new rail link relate to the project's impact on landscape, noise, safety, and emissions of all kind.

Landscape effects are primarily related to demand changes on the housing market, as people do not take into account the loss of open agricultural and natural landscapes when looking for a place to live. In a free land market, these external effects would cause too much land to be allocated to housing. Restrictive spatial planning in the Netherlands aims to avoid this; it is successful if the external effects are fully internalized in housing prices. Although there is evidence of a considerable price differential in

technically comparable owner-occupied housing between the urban and rural parts of the Netherlands (Creusen 1999), it goes too far to say that these external effects are fully internalized. One major reason is that the Dutch government also subsidizes rental housing programs and mortgage interest rates.

In fact, especially in the core-periphery variants, the relocation of housing and jobs is expected to lead to less pressure on open landscapes in the Randstad and more pressure in the North, whereas in the urban-conglomeration variants the pressure in the Randstad is expected to increase. Estimates of costs and benefits due to imperfections on the housing market are based on shadow prices for land derived in a previous study (Elhorst et al. 1999) and are related to the spatial redistribution of the working population, as reported in Section 3.2. 
Three other external effects must be considered. First, the construction and operation of a new rail link causes direct external costs. Second, the substitution of public transport for car transport causes indirect external benefits. Third, the relocation of employment and population may cause indirect external cost or benefits in different regions. Although many of these effects are quantified, only $\mathrm{CO}_{2}$ and $\mathrm{NO}_{x}$ emission effects (Van Wee et al. 2003) and noise pollution (Gotink 2004) could be valued in monetary units, using various shadow prices.

Discounting and adding all monetized cost and benefits gives the net present value (NPV). In Table 1, all monetized cost and benefits and the NPV are calculated for 2010 (the assumed starting year of the construction), using prices of 2000 and a social discount rate of four percent, over both a 30 -year period and a 50-year period. ${ }^{7}$ The four percent rate and 30-year period are standard in Dutch social cost-benefit analysis (CPB/NEI 2000). The problem with the 30-year period is that it does not cover the lifespan of the projects. The problem with our alternative 50 -year period is that the social discount rate of four percent does not cover the risks of the projects. Therefore, we have also calculated the internal discount rate over both periods.

\subsection{Integral cost-benefit analysis results}

From Table 1 it can be seen that the total benefits of the urban-conglomeration projects are almost twice as large as those of the core-periphery projects. Furthermore, it can be seen that the composition of the benefits is very different.

The urban-conglomeration projects produce larger time benefits, negative instead of positive spatial labor market relocation benefits, greater labor market size and matching benefits, and larger international benefits. Moreover, both direct congestion and emissions are reduced, due to substitution between car and rail. This is especially notable in the case of the inner ring project, which has far fewer passengers and less exploitation revenues than the outer ring project, due to the fact that it mainly connects the edges of the large cities (see Figure 1). The majority of the inner ring passengers, however, leave their cars because of the relatively large time benefits, whereas the outer ring (connecting city centers) attracts many more new passengers and passengers who previously used other forms of public transport, leading to benefits of reduced congestion and emissions.

The core-periphery projects mitigate congestion only indirectly as people and jobs leave the Randstad. Since substitution from cars is negligible and magnetic levitation

\footnotetext{
${ }^{7}$ Additionally, construction of the new rail link is assumed to take place over the period 2010-2015, with 33,17,20, 20 and 10 percent of the cost occurring per subsequent year in the urban-conglomeration projects, and with $10,15,30,30$ and 15 percent per year in the core-periphery projects (NEI 2000, 2001). The exploitation cost and revenues, and time benefits are assumed to start at 100 percent from 2016 onwards. Indirect economic effects are assumed to rise over a five-year period, starting at 20 percent in 2016 and reaching 100 percent in 2020.
} 
uses about three to four times as much energy (Van Wee et al. 2003), the emission effects for the core-periphery projects are negative instead of positive. Compared to the urban-conglomeration projects, however, they have positive instead of negative spatial labor market relocation benefits. This is due to the fact that these projects decrease the pressure on the tight Randstad labor market and decrease unemployment in the rest of the country, as reported in section 3.2. In addition to this, the south-east variant has relatively large time benefits for business/shopping and high open landscape benefits, as it uses the less vulnerable new polders for longer distance suburbanization instead of suburbanization into the valuable old historic landscapes in the so-called "Green Heart of the Randstad."

The reported impact of noise pollution depends on factors such as the driving speed, the number of passages and the number of people hindered. In addition, this impact depends on whether the new railway line is combined with existing railway or existing road infrastructure. The impact of the inner variant of the urbanconglomeration project is relatively low, because it mainly connects city edges and is almost completely combined with existing road infrastructure with an independent continuous level of noise pollution. The noise impact of the outer variant of the urbanconglomeration project is almost ten times as large, because it has more stops at innercity stations and because it is mainly combined with existing railway infrastructure that produces non-synchronized, discontinuous noise pollution.

The investment costs, of course, depend on the length of the alignments and on the extent to which they have to be constructed in an urban or a rural environment. The latter factor explains why the urban-conglomeration projects are more expensive, and also why the outer ring connecting city centers is more expensive than the inner ring connecting the edges of the main cities. The exploitation costs of the urbanconglomeration projects are much higher than those of the core-periphery projects, as their operational frequency is 10 versus six trains per hour. Consequently, exploitation costs exceed the exploitation revenues in the urban-conglomeration projects.

\subsection{Estimation uncertainties}

This section briefly considers the main uncertainties involved in estimating costs and benefits for these projects. The results obtained with respect to housing migration may have been overestimated, since they have been calculated at currently prevailing prices instead of at higher prices and assume that positive demand shifts on the housing market will be accommodated - which is unlikely in the heavily regulated Dutch housing market. However, the results may prove to have been underestimated if the public's willingness to commute continues to grow.

The results obtained with respect to employment changes and labor migration may have been underestimated, as the NEG model does not take account of scale, cluster, 
and imago effects. Finally, interactions between shifts in labor supply and shifts in labor demand are not yet incorporated into the labor market regime switch model. As a result, some of the net productivity and net job effects on the labor market may have been overestimated.

Although important results have been reached by means of carefully combining the five different modeling approaches, a further integration of the models used is definitely called for. This of course will change the specific empirical outcomes of our analysis, but we believe that it will not change our main conclusions.

\section{Concluding evaluation}

\subsection{Profitability of Maglev falls short}

When all monetized costs and benefits are summed over a 30-year period, none of the projects has a positive net present value (NPV). With a more realistic 50 -year period the NPV increases significantly, but remains negative for all projects. For both periods, it is shown that the inner ring variant clearly outweighs the outer ring variant of the urbanconglomeration project, while the south-east variant clearly outweighs the north-west variant of the core-periphery project. However, the internal discount rate of all projects still falls short of the required four percent, so none of the considerable risks of the new magnetic levitation technology are covered. Note that this does not imply that spatially comparable regular rail or high speed rail alternatives would be better than the Maglev alternatives considered here. ${ }^{8}$

The above conclusion on the four Maglev proposals could change if the nonmonetized costs and benefits were large, but that is not the case. Compared to the additional economic benefits that are covered, we believe the additional, non-modeled economic benefits to be minor. As to the non-monetized external cost, first attempts to evaluate the impacts on safety and the natural environment have shown that these are relatively small and not necessarily negative (Van Wee et al. 2003). The “-/+" sign in the urban-conglomeration projects in Table 1 is used to indicate that the non-monetized external effects are negative with respect to the build and natural environment, and positive with respect to safety, such that the overall sign is uncertain.

Finally, the effect on national efficiency - measured by the sum of the NPV and all non-monetized effects—should be balanced against the effect on interregional equity. This is a typical political evaluation that, if considered relevant, weighs in favor of,

8 Only in the case of the south-east variant has a systematic CBA comparison been made (Elhorst and Oosterhaven 2001). It shows that a high-speed rail variant capable of $300 \mathrm{~km} /$ hour speeds and a regular-speed rail variant with capable of $160 \mathrm{~km} /$ hour are, respectively, cheaper and much cheaper in terms of cost, and generate, respectively, less and much less benefits. This leads to the interesting result that the NPVs of the regular- and high-speed rail alternatives are higher, whereas their internal rates of return are smaller than that of the Maglev alternative. 
especially, the north-west variant of the core-periphery project, and slightly against both urban-conglomeration projects.

Table 1 also shows that the effects of transport improvements are strongly dependent on specific regional circumstances and conditions. All results are calculated in deviation from the moderate "European Co-ordination" economic development scenario of the CPB (1997). This baseline scenario, however, describes only one of the possible national economic futures. Other futures are described in the more pessimistic macro-economic "Divided Europe" scenario and the more optimistic "Global Competition" scenario (ibid 1997).

The upper part of Table 2 shows that the effects of transport improvements are also dependent on the general national and global economic conditions. In the Divided Europe growth scenario, the negative net present value (NPV) of all projects becomes worse, on average by 28 percent. As the unemployment rate in the Divided Europe scenario is eight percent, not only peripheral regions but also the urban core is characterized by a labor supply surplus. Under this condition, new (international) labor demand can be satisfied without displacing other jobs, whereas geographical relocation benefits disappear. In the Global Competition scenario, the NPV of all projects improves (except for the inner variant), with on average 13 percent. The differences in size and composition of the benefits between this scenario and the European Coordination scenario are less remarkable.

\subsection{No uniform ratio of additional to direct benefits}

An important methodological and empirical issue is the ratio between the benefits that are calculated with our (almost) integral social cost-benefit analysis and the benefits that would have been calculated under the condition of perfect competition and a closed economy. Using a purely theoretical model, Newbery (quoted from SACTRA 1999, p. 101) argues that the potential bias in conventional partial transport CBA's, due to imperfect competition, is generally too small to worry about, as the truly additional benefits only amount to 2.5 percent of the direct transport benefits. By contrast, Venables and Gasiorek (also in SACTRA 1999, p. 101), using a more elaborate theoretical model, find that most model permutations show additional economic benefits of around 30 percent, while very few permutations show additional economic benefits that exceed 60 percent. However, empirical evidence corroborating these ratios is lacking. Moreover, both approaches assume a clearing labor market and a closed economy. ${ }^{9}$ The present study offers the first possibility to underpin these theoretical simulations with ex ante empirical data about real projects, while also accounting for labor market imperfections and cross-border effects.

\footnotetext{
9 Newbery also does not deal with additional welfare accruing from linkage and agglomeration effects, and the entry and exit of firms (SACTRA 1999, p. 101).
} 
Table 2: Net present values of the monetized costs and benefits, and additional to direct benefit ratios, for the period 2010-2060, under different macro-economic scenarios.

\begin{tabular}{lrrrr} 
& $\begin{array}{r}\text { Inner ring } \\
\text { Randstad }\end{array}$ & $\begin{array}{r}\text { Outer ring } \\
\text { Randstad }\end{array}$ & $\begin{array}{r}\text { Amsterdam- } \\
\text { Groningen, } \\
\text { north-west }\end{array}$ & $\begin{array}{c}\text { Amsterdam- } \\
\text { Groningen, } \\
\text { south-east }\end{array}$ \\
\hline $\begin{array}{l}\text { Net present values (millions of Euros): } \\
\text { Basic scenario: }\end{array}$ & & & & \\
$\begin{array}{l}\text { European Coordination } \\
\text { Pessimistic scenario: }\end{array}$ & -532 & -2374 & -2880 & -1020 \\
$\begin{array}{l}\text { Divided Europe } \\
\text { Optimistic scenario: }\end{array}$ & -1705 & -2717 & -3108 & -1172 \\
$\begin{array}{l}\text { Global Competition } \\
\text { Additional economic to direct transport benefits (percentages): }\end{array}$ & & & & \\
$\quad$ Basic scenario: \\
$\begin{array}{l}\text { European Coordination } \\
\text { Pessimistic scenario: }\end{array}$ & 8 & 6 & 32 & 34 \\
$\begin{array}{l}\text { Divided Europe } \\
\text { Optimistic scenario: }\end{array}$ & -602 & -1823 & -2770 & -731 \\
Global Competition & 7 & 6 & 32 & 34 \\
\hline
\end{tabular}

The lower part of Table 2 shows that the additional benefits in the core-periphery projects are much larger than in the urban-conglomeration projects. This can be explained in part by the fact that that price mark-ups above marginal cost-due to monopolistic competition-were estimated to range from less than 20 percent in central regions to over 30 percent in peripheral regions, which is comparable with the figures found by Harris (16 to 29 percent, quoted in SACTRA 1999, p. 101). A second explanation is that our analysis not only covers product markets, but also labor markets, which from a spatial viewpoint are far more imperfect than product markets. In the core-periphery projects almost every additional effect with regard to these markets appears to be positive, whereas several are negative in the case of the urbanconglomeration projects. Taking all additional economic benefits together, Table 2 shows the additional benefits to lie between +32 percent and +38 percent of the direct transport benefits in the case of the core-periphery projects and between -1 percent and +8 percent in the case of the urban-conglomeration projects. These last numbers are clearly different from those in the theoretical studies discussed above.

This leads to the following more general conclusions. First, the hypothesis that the 
additional economic benefits are too small to worry about must be rejected. Second, the use of a uniform "additional economic benefits to direct transport benefits" ratio to approximate these additional benefits must also be rejected. Third, although having negative additional benefits is theoretically recognized as possible, no study has yet been able to specify the circumstances under which this might occur. Our study proves this to be empirically possible, and relates it to adverse impacts on tight and loose regional labor markets.

\subsection{Contribution to the literature}

The contribution of this paper to the literature is twofold. First, it is the first study that has attempted to measure the comprehensive net total of all social costs and benefits of new transport infrastructure taking account of the effects of imperfect competition and an open economy. The results show that a uniform ratio to derive the additional economic benefits from the direct transport benefits does not exist, as that ratio proves to be strongly dependent on the type of regions connected, the alignment at hand, the type of market imperfections included in the analysis and the general future state of the economy. Second, it is one of the first studies that has attempted to measure this net total for magnetic levitation systems. The empirical results show that we cannot yet give a positive answer to the basic question whether the Maglev system is worthwhile, since the internal rate of discount falls short of the required $4 \%$ for four quite different variants under three different future sets of economic conditions, even when a 50-year time horizon is used.

\section{Acknowledgements}

This investigation has been completed in co-operation with TNO in Delft, Free University in Amsterdam, Technical University in Dresden, Netherlands Economic Institute in Rotterdam, Buck Consultants International in Nijmegen and NYFER in Breukelen. Data on travel times have been made available by AND Data Solution, the Hague Consultancy Group and our students. Parts of this study were commissioned by the Dutch Ministries of Transport and Economics, and were co-executed with Ward E. Romp. The authors are very grateful to all these organizations and people. They also thank three anonymous referees of this Journal for their very useful comments.

\section{References}

BCI (2001). Strategische internationale effectenstudie Rondje Randstad. Technical report, Buck Consultants International, Nijmegen (Netherlands).

Bell, C. (2003). Development policy as public finance. Oxford University Press, Oxford. 
Boeri, T. (1990). Beyond the rule of thumb: Methods for evaluating public investment projects. Westview Press, Boulder, CO.

Bröcker, J. (1999). Trans-European effects of "Trans-European Networks": A spatial CGE analysis. University of Technology, Dresden.

Button, K. (1993). Transport economics. Edward Elgar, Cheltenham (UK).

CPB (1997). Economie en fysieke omgeving, beleidsopgaven en oplossingsrichtingen 1995-2020. Technical report, Central Planning Bureau, The Hague.

$\mathrm{CPB} / \mathrm{NEI}$ (2000). Evaluatie van infrastructuur projecten. Leidraad voor kosten-baten analyse. Technical report, Central Planning Bureau, The Hague.

Creusen, H. (1999). CBP Report 1999, volume 2, chapter Housing construction: Between competition and regulation, pp. 20-23.

Daly, A. (2000). National models. In: D. Henher and K. Button, eds., Handbook of transport modelling, pp. 421-432. Elsevier, Amsterdam.

Drèze, J. and N. Stern (1987). Theory of cost-benefit analysis. In: A. Auerbach and M. Feldstein, eds., Handbook of public economics, volume 2, pp. 909-989. Elsevier.

EC (2002). Guide to cost-benefit analysis of investment projects. European Commission, DG Regional Policy, Brussels.

Elhorst, J. and J. Oosterhaven (2001). Herziening rug-kba zuiderzeelijn varianten. In: Verdieping maatschappelijke kosten-baten analyse Zuiderzeelijn. Buck Consultants International, The Hague.

- (2006). Forecasting the impact of transport improvements on commuting and residential choice. Journal of Geographical Systems, 8: 39-59. doi:10.1007/ s10109-005-0015-4.

Elhorst, J., J. Oosterhaven, F. Sijtsma, and D. Stelder (1999). Welfare effects of spatial deconcentration: A scenario for the Netherlands. Tijdschrift voor Economische en Sociale Geografie [Journal of Economic and Social Geography], 90: 17-31. doi:10. 1111/1467-9663.00047.

Gotink, A. (2004). Monetaire waardering van geluidsoverlast veroorzaakt door de magneetzweefbaan. Master's thesis, Dept. of Economics, University of Groningen.

Jansson, J. (2000). Transport infrastructure: The investment problem. In: J. Polak and A. Heertje, eds., Analytical transport economics: An international perspective, pp. 141-171. Edward Elgar, Cheltenham (UK).

Knaap, T. and J. Oosterhaven (2008). Welfare effects of infrastructure: A spatial equilibrium evaluation of Dutch railway proposals. In: H. Gunn, ed., Economic impacts of changing accessibility. Elsevier. (forthcoming).

Krugman, P. (1991). Geography and trade. MIT Press and Leuven University Press, London.

NEI (2000). KBA van een snelle verbinding naar het Noorden. Netherlands Economic Institute, Rotterdam.

(2001). KKBA van een snelle verbinding tussen de vier grote steden: 'Rondje Rand- 
stad'. Netherlands Economic Institute, Rotterdam.

Oosterhaven, J. (2005). Spatial interpolation and decomposition of multipliers. Geographical Analysis, 37: 69-84. doi:10.1111/j.1538-4632.2005.00522.x.

Oosterhaven, J. and T. Knaap (2003). Spatial economic impacts of transport infrastructure investments. In: A. Pearman, P. Mackie, and J. Nellthorp, eds., Transport projects, programmes and policies: Evaluation needs and capabilities, pp. 87-105. Ashgate, Aldershot.

Oosterhaven, J. and W. Romp (2003). Indirect economic effects of new infrastructure: A comparison of dutch high speed rail variants. Tijdschrift voor Economische en Sociale Geografie [Journal of Economic and Social Geography], 94: 439-452. doi:10.1111/ 1467-9663.00272.

Overman, H. and D. Puga (2002). Unemployment clusters across Europe's regions and countries. Economic Policy, pp. 116-147.

Rietveld, P. and P. Nijkamp (2000). Transport infrastructure and regional development. In: J. Polak and A. Heertje, eds., Analytical transport economics: An international perspective, pp. 208-232. Edward Elgar, Cheltenham (UK).

Rothengatter, W. (2000). External effects of transport. In: J. Polak and A. Heertje, eds., Analytical transport economics: An international perspective, pp. 79-116. Edward Elgar, Cheltenham (UK).

SACTRA (1999). Transport and the economy. Technical report, Standing Advisory Committee on Trunk Road Assessment, TSO, London.

TNO, RUG, VU, and TUD (2000). Indirecte effecten Zuiderzeelijn, Hoofdrapport. Technical report, TNO Inro, University of Groningen, Free University, Technical University Dresden, Delft (Netherlands).

van Wee, B., R. van den Brink, and H. Nijland (2003). Environmental impacts of high-speed rail links in cost-benefit analyses: A case study of the Dutch Zuider Zee line. Transportation Research Part D, 8: 299-314.

Venables, A. (1996). Equilibrium locations of vertically linked industries. International Economic Review, 37: 341-359.

Vuchic, V. and J. Casello (2002). An evaluation of Maglev technology and its comparison with high-speed rail. Transportation Quarterly, 56: 33-49. 